\title{
Kasvi-indigon käyttö tekstiilisuunnittelussa
}

Kirsi Niinimäki, Aino Gröhn, Hanna Alanen, Eija Lummi, Eila Anttila, Emma Boström, Sami Vulli, Sirpa Kinnunen.

EVTEK Muotoiluinstituutti, Kasvivärien tuotekehitysprojekti, Lummetie 2, 01300 Vantaa kirsi.niinimaki@iad.evtek.fi

\section{Johdanto}

EVTEK Muotoiluinstituutissa meneillään olevan Kasvivärien tuotekehitysprojektin puitteissa on tutkittu ja koekäytetty MTT:n viljelemiä värimorsinko- (Isatis Tinctoria) ja japanin väritatarliemiä (Polygonum Tinctorium) tekstiilikuitujen värjäyksessä. Ensimmäiset koevärjäykset tehtiin talvella 2001-02 kesän 2001 Japanin väritatarsadosta. Talvella 2002-03 on koevärjätty kesällä 2002 viljeltyä värimorsinkoa. Värjäyksiä on tehty käsityömäisessä mittakaavassa, mutta myös teollisina värjäyksinä sekä langoille että kankaille. Talven 2002-03 aikana ovat EVTEK:in opinnäytetyön tekijät hyödyntäneet kasvi-indigolla värjättyjä kankaita ja lankoja omissa suunnittelupainotteisissa opinnäytetöissään. Valmiit mallistot ja tuotteet ovat olleet mukana Kasvivärien tuotekehitysprojektin koemarkkinointilaisuuksissa elokuussa Helsingin muotimessuilla sekä syyskuussa Habitare messuilla 2003.

Kotimaiset kasvi-indigot ovat herättäneet kiinnostusta. Suomalainen sininen värisävy voisi muodostua yhdeksi nostetta antavaksi kilpailutekijäksi suomalaiselle tekstiiliteollisuudelle. Suomalainen sininen suomalaisella ekopellavamateriaalilla, 100\% suomalainen ympäristömyötäinen tuote, voisi löytää tehokkaan markkinoinnin avulla varteenotettavat markkinat esim. Keski-Euroopan ympäristötietoisten kuluttajien keskuudessa.

\section{Käsityömäinen värjäys}

Opiskelijat Aino Gröhn ja Hanna Alanen tutkivat työssään "Värimorsinko -Euroopan sininen kasviväri" värimorsingon käsityömäistä värjäystä. Värimorsinko saatiin MTT:Itä valmiiksi uutettuna liuoksena kahtena eri vahvuutena. Opiskelijat koevärjäsivät pienimuotoisesti eri menetelmin värimorsingolla. Laimeampaa morsinkoliuosta (eristys tehty viileäeristyksenä)myös kokeiltiin vahventaa, tummentaa värisävyä, hapottamalla. Vahventaminen tapahtui siten, että liuoksen $\mathrm{pH}$ laskettiin sitruunahapon tai etikkahapon avulla. PH:n lasku 4:ään aiheuttaa väriaineen, indigon laskeutumisen astian pohjalle, jolloin laimeampi ja kellertävää väriainetta sisältävä liuos jää astian pinnalle ja se voidaan kaataa pois. Näin vahvennetulla väriliuoksella värjättäessä aikaansaadaan tummempaa ja puhtaampaa sinistä väriä. Poiskaadetullakin väriliemellä voidaan värjätä ja aikaansaada haaleita turkooseja värisävyjä. Käsityömäisessä värjäyksessä kokeiltiin eri materiaalien ja kuitujen värjäytyvyyttä värimorsingolla. Yleistäen voidaan sanoa että puhtaimmat siniset sävyt aikaansaadaan pellavalle ja puuvillalle. Valkuaisainekuidut silkki ja villa taas värjäytyy hieman vihreämmän siniseksi vaikka käytetään samoja reseptejä kuin selluloosakuiduille.

Hauskoja efektejä saadaan aikaiseksi materiaaleille, jotka sisältävät kahta tai useampaa eri kuituja. Esim. viskoosin ja puuvillan, puuvillan ja lycran, villan ja turvekuidun yhdistelmille aikaansaadaan mielenkiintoisia meleerattuja värjäystuloksia.

\section{Kankaiden teollisuusvärjäys}

Värimorsingolla värjättiin teollisesti kankaita Laikola Oy:n värjäämössä Kyröskoskella. Värjäys tapahtui pienessä haspel-koneessa, jonne värimorsinkolientä laitettiin 230 I ja värjättävää materiaalia 10 kg. Haspel- koneella värjäyttäessä kangasta käsitellään köysimuodossa, eli kangas on vapaasti laskostuneena ja päistään kiinni ommeltuna. Menetelmän tarkoituksena on kankaan värjäyksen lisäksi antaa sille mekaanista käsittelyä. Haspelkoneessa kangas kulkee eteenpäin haspelin pyöriessä ja siirtäessä kangasta nykäyksittäin eteenpäin. Kangas laskostuu väriliemeen värjäysaltaan pohjalle, josta se sitten nousee aina uudelleen haspelin vetämänä nestepinnan yläpuolelle. Värjäykseen oli ommeltu yhteen erilaatuisia kankaita yhtenäiseksi "köydeksi". Väriliemi lämmitettiin 50C:een. Väriluoksen pH säädettiin 10:een lipeällä, jonka jälkeen lisättiin natriumditioniittia suhteessa $100 \mathrm{~g} / 10$ litraa. Natriumditioniitin annettiin vaikuttaa noin 20 minuuttia ennen värjäyksen käynnistämistä. Värjäyksen aikana natriumditioniittia ja lipeää lisättiin kaksi kertaa kyypin ylläpitämiseksi. Haspel-koneessa kangas kiertää koko ajan tasaisesti, kuitenkin aina 
välillä ilman kanssa kosketuksissa olleen. Näin happea kulkeutuu väriliemeen ja siksi kemikaaleja on syytä lisätä värjäyksen aikana kyypin ylläpitämiseksi aktiivisena. Värjäys kesti 30 minuuttia, jonka jälkeen väriliemi laskettiin pois ja tilalle koneeseen laitettiin puhdas huuhteluvesi, jossa sinisen värin pitäisi kehittyä vedessä olevan hapen avulla. 15 minuutin kuluttua väri ei näyttänyt tarpeeksi siniseltä, jolloin koneeseen huuhteluveden sekaan laitettiin hieman vetyperoksidia, joka nopeuttaa värin hapettumista ja sininen väri tulikin nopeasti esiin. Yhteensä hapetus koneessa kesti 30 minuuttia. Viimeiseen huuhteluveteen lisättiin etikkahappoa $\mathrm{pH}:$ n neutraloimiseksi sekä huuhteluainetta kankaan pehmentämiseksi. Värjäystulos oli täydellisen tasainen ja hyvin puhtaan vaalean sininen. Eri kuitusisältöisillä kankailla lopputulos oli eri tummuusasteisia sinisiä sävyjä( vaaleampia ja tummempia sinisiä).

\section{Teollisuusvärjäys pellavalangoille}

Ensimmäinen pellavalankojen teollinen koevärjäys tehtiin Wetterhoff Oy:n värjäämössä talvella 2002 kesän 2001 MTT:n Japanin väritatar eli Polygonum-uutteesta (Polygonum Tinctorium). Värjättävänä lankana oli Wetterhoff Oy:n aivina 16 pellavalanka. Värjäys tehtiin Henrikssen Gru 5tyyppisellä vyyhtivärjäyskoneella. Värjäyksen suoritti värimestari Erkki Yrjölä Wetterhoff Oy:stä ja värjäyksen dokumentoi Eila Anttila HAMK:sta. Esipestyä pellavamateriaalia oli $10 \mathrm{~kg}+$ $6 \mathrm{~kg}$ (kakkosvärjäykseen) ja värilientä 200l. Värjäyskone oli niin suuri, että sinne piti lisätä vielä 100 I vettä, jotta värjäysliemen korkeus saatiin tarpeeksi ylös. Väriliemen pH säädettiin kidesoodalla 9,2:een. Värjäysliemi kuumennettiin $50 \mathrm{C}$. Liemeen lisättiin 3,5kg natriumditioniittia $(100 \mathrm{~g} / 10 \mathrm{I})$. Natriumditioniitin annettiin vaikuttaan 30 minuuttia ennenkuin värjäys käynnistettiin. Kastellut langat $(10 \mathrm{~kg})$ nostettiin liemeen vyyhtikehikossa. Lankojen annettiin olla liemessä 30 minuuttia ja lämpötila pidettiin tänä aikana 50C. Värjäyskone liikutteli lientä edestakaisin, mutta vyyhdet pysyivät koko ajan liemessä eikä liemen pinta liikkunut juuri lainkaan, joten liemeen ei päässyt juurikaan happea. Värjäyksen jälkeen langat nostettiin hapettumaan, jolloin keltainen väri nopeasti muuttui siniseksi. 30 minuutin hapetuksen jälkeen langat huuhdeltiin kylmällä ja lämpimällä vedellä ja neutraloitiin etikalla.

Samalla värjäysliemellä voidaan tehdä useampia värjäyskertoja, joten kokeilimme jo kertaalleen värjätyllä polygonum-liemellä kakkosvärjäystä. Ensimmäisen värjäyksen jälkeen liemen pH oli 8,2. Liemeen lisättiin kalsinoitua soodaa, jotta pH saatiin nousemaan 9,3. Tässä vaiheessa myös natriumditioniittia lisätään hieman liemen uudelleen aktivoimiseksi. Yleensä $10 \mathrm{~g} / 10$ I lisäys riittää. Kakkosvärjäyksessä värjättiin $6 \mathrm{~kg}$ pellavalankoja. Muuten värjäys eteni kuten ykkösvärjäyskin. Lopputuloksena oli hieman vaaleampi sininen värisävy kuin ensimmäisellä värjäyskerralla.

Tammikuussa 2003 värjäys toistettiin Wetterhoffilla pellavalangoille, mutta tällä kertaa MTT:n värimorsinkoliemellä kesän 2002 sadosta. Pellavalangat värjättiin nyt hieman pienemmässä värjäyskoneessa. Värimorsinkoliemi oli kylmäeristuksen tulosta, joten ensin liemi hapotettiin, $\mathrm{pH}$ laskettiin noin 4,5:een, jotta vahvempi väriliemi saatiin laskeutumaan pohjalle. Liemistä kaadettiin pois päältä seisotuksen jälkeen noin 1/3 osa laimeaa lientä, jota ei käytetty värjäykseen. 300 litran värjäysliemellä värjättiin 10kg lankaa, joka värjäytyi kauniin siniseksi (hieman vihertävä lopputulos) Kakkosvärjäystä ei tehty, vaikka liemi oli niin vahvaa, että sekin olisi varmasti tuottanut hyvän lopputuloksen.

\section{Värjättyjen lankojen testaus}

Polygonumilla värjätyt pellavalangat testasi Eija Lummi TAMK:sta (Tampereen Ammattikorkeakoulu). Hän testasi opinnäytetyössään "Väritataruute ja tiivisteväriaineet" lankojen valon-, pesun- ja hankauksenkestoja.

Värin pesunkeston määritys tehtiin standardin SFS-EN ISO 105-C06 mukaan. Testi määrittää erilaisten materiaalien värien pesunkeston tavanomaisille tekstiileille käytettävissä koti- ja pesulapesun ohjelmissa. Pesunkestot testattiin sekä standardipesuaineella että neutraalilla Elokuun pesuaineella Linitest-laitteella.

Värin hankauksenkeston määritys tehtiin standardin SFS-EN ISO 150-X12 mukaan A.A.T.C.C Crockmeter laitteella. Testi määrittää kuinka paljon väri kestää hankausta ja kuinka se tuhrii muita kankaita. Hankauksenkesto tehtiin sekä kuivalle että kastellulle materiaalille. Värin pesun- ja hankauksenkestotestissä verrataan näytteisiin ommeltuja testikankaita ja yksistään pestyjä 
monikuitukankaita harmaa-valkea asteikkoon. Näin saadaan tahriutumisen arvosana. Näytteet arvioidaan asteikolla 1-5, josta tahriintumaton materiaali saa arvosanan 5. Jokainen testattu materiaali (asetaatti, puuvilla, polyamidi, polyesteri, akryyli, villa) saa oman arvosanansa. Seuraavaksi näytettä verrataan pesemättömään näytteeseen harmaa-asteikolla 1-5, joista 5 on paras arvosana. Hankauksenkesto arvioidaan asteikolla 1-5, joista 5 on paras.

Värin valonkestotestit tehtiin James H.Herla-laitteella standardin ISO 105-B03 mukaan. Testi määrittää, kuinka paljon väri muuttuu valon vaikutuksesta.

Pellavalankojen värin hankauksenkestot ovat erittäin hyvät sekä kuiva- että märkähankauksessa. Värin pesunkestotulokset ovat myös hyvät. Suositeltava pesulämpötila on $60 \mathrm{C}$, mutta pesuaineella ei ole merkitystä. Toisaalta värisävyn muutos pesun jälkeen on saanut arvosanaksi 3 , joka tarkoittaa sitä, että langan sininen sävy hieman muuttuu ensimmäisessä pesussa.

\begin{tabular}{|c|c|c|c|c|c|c|c|c|c|c|c|}
\hline $\begin{array}{l}\text { polygonumilla } \\
\text { värjätty } \\
\text { materiaali }\end{array}$ & $\begin{array}{l}\text { pesu- } \\
\text { lämpötila } \\
\text { ja } \\
\text { pesuaine }\end{array}$ & $\begin{array}{l}\text { tahriu- } \\
\text { tuminen } \\
\text { asetaatti }\end{array}$ & $\begin{array}{l}\text { tahriu- } \\
\text { tuminen } \\
\text { puuvilla }\end{array}$ & $\begin{array}{l}\text { tahriu- } \\
\text { tuminen } \\
\text { polyamidi }\end{array}$ & $\begin{array}{l}\text { tahriu- } \\
\text { tuminen } \\
\text { polyesteri }\end{array}$ & $\begin{array}{l}\text { tahriu- } \\
\text { tuminen } \\
\text { akryyli }\end{array}$ & $\begin{array}{l}\text { tahriu- } \\
\text { tuminen } \\
\text { villa }\end{array}$ & $\begin{array}{l}\text { värisävyn } \\
\text { muutos }\end{array}$ & $\begin{array}{l}\text { hankauk- } \\
\text { senkesto } \\
\text { kuiva }\end{array}$ & $\begin{array}{l}\text { hankauk- } \\
\text { senkesto } \\
\text { märkä }\end{array}$ & $\begin{array}{l}\text { valon- } \\
\text { kesto }\end{array}$ \\
\hline $\begin{array}{l}\text { pellava } \\
\text { ykkösvärjäys }\end{array}$ & $\begin{array}{l}60 \mathrm{C} \\
\text { standardi }\end{array}$ & $4-5$ & 5 & $3-4$ & 5 & 5 & 5 & 3 & $4-5$ & $3-4$ & 3 \\
\hline $\begin{array}{l}\text { pellava } \\
\text { ykkösvärjäys }\end{array}$ & $\begin{array}{l}60 \mathrm{C} \\
\text { elokuu }\end{array}$ & 4 & 5 & $3-4$ & 5 & 5 & 5 & 3 & $4-5$ & $3-4$ & 3 \\
\hline $\begin{array}{l}\text { pellava } \\
\text { kakkosvärjäys }\end{array}$ & $\begin{array}{l}60 \mathrm{C} \\
\text { standardi }\end{array}$ & $4-5$ & 5 & $3-4$ & 5 & 5 & 5 & 3 & 5 & $4-5$ & 2 \\
\hline $\begin{array}{l}\text { pellava } \\
\text { kakkosvärjäys }\end{array}$ & $\begin{array}{l}60 C \\
\text { elokuu }\end{array}$ & 4 & 5 & $3-4$ & 5 & 5 & 5 & 3 & 5 & $4-5$ & 2 \\
\hline
\end{tabular}

\section{Siniset vaatekokoelmat}

EVTEK Muotoiluinstituutin vaatesuunnittelun opiskelijoiden Aino Gröhnin ja Hanna Alasen opinnäytetyössä "Värimorsinko - Euroopan sininen värikasvi " tutkittiin kotimaassa viljellyn värimorsingon (Isatis Tinctoria) tuotteistamista. Aino ja Hanna hyödynsivät sekä itse käsin värjäämiään että teollisesti värjättyjä kankaita suunnitellessaan ja toteuttaessaan omat vaatemallistonsa. Värjäyskokeilut sekä kotimaisella värimorsingolla että maahantuodulla luonnon indigolla (Indigofera Tinctoria) toimivat ideapohjana mallistoissa käytettävien materiaalien ja värjäysmenetelmien suunnittelussa. Tavoitteena oli suunnitella kaksi modernia, teollisestikin toteuttamiskelpoista, noin viiden asukokonaisuuden vaatemallistoa. Naisten ja miesten mallistojen suunniteltiin sisältävän sekä teollisesti värjättyjä että käsinvärjättyjä materiaaleja. Mallistot esiteltiin Helsingin muotimessuilla elokuussa 2003. Kummankin tekijän asukokonaisuudet kaavoitti ja ompeli Reetta Myllymäki.

Aino Gröhn keskittyi työssään miesten vaatemalliston suunnitteluun. Yksi suunnitteluun vahvasti vaikuttaneista teemoista oli suomalaisuus. Kotimaassa viljelty sininen värikasvi, sininen väri ja suomen sininen antoivat inspiraation suomaisen miehen vaatteisiin, joissa tietty yksinkertaisuus ja pidättyvyys, vähäeleisyys ja hiljaisuus toistuvat vaatteiden suunnittelun teemoissa. Aino käytti mallistossaan teollisesti Laikolassa värjättyjä kankaita sekä itse käsin tumman siniseksi värjäämiään villakankaita. Hän nimesi vaatteet "Happy Feeling Blue"-kokoelmaksi suomalaiselle miehelle.

Hanna Alasen naistenvaatemallistossa suunnittelun lähtökohtina ovat olleet sinisen värin ja sen kohtaaman materiaalin yhteiselo. Mallistossa naiselliset pehmeät muodot ja vahva kädenjälki tulevat persoonallisesti esille. Materiaaleihin on haettu elävyyttä värjäämällä niitä käsin epätasaiseksi, sekä reservipainotekniikoilla kuvioimalla tekstiilipintoja. Karheat luonnonmateriaalit rinnastuvat ohuempiin. Eläväpintainen pellava luo pohjan mallistolle. Malliston nimeksi suunnittelija on antanut "Sinikka"

\section{Kaste-tekstiilimallisto}

EVTEK Muotoiluinstituutin tekstiilisuunnittelun opiskelija Emma Boström suunnitteli ja tuotti keväällä 2003 malliston sisustustekstiilejä. Malliston materiaalina oli kotimainen ekopellavalanka, joka oli värjätty MTT:ssä viljellyllä ja uutetulla värimorsinkoliuoksella. Värimorsinkovärjäys tehtiin Wetterhoff Oy:llä teollisena kyyppivärjäyksenä tammikuussa 2003. Tekstiilimallisto kudottiin 
Jokipiin pellavassa valkoiseen vakiopellavaloimeen. Malliston suunnitteluun Emma haki vaikutteita 1960- ja 1970-lukujen kuviomaailmasta. Selkeät geometriset kuviot ja yksinkertainen muotokieli, joka perustuu ympyrään, luovat tehokkaan ja hyvin trendikkään lopputuloksen. Mallistoon kuuluu kaitaliinoja, keittiöpyyhkeitä sekä kokoleveä pöytäliinamalli. Tuotteet olivat esillä Habitare messuilla syyskuussa 2003 ja ovat nyt myynnissä mm. Design Forumissa Helsingissä.

\section{Digitaaliset tekstiililaitteet koekäytössä}

EVTEK Muotoiluinstituutin opiskelija Sami Vulli testasi tekstiilien digitaalisen kangastulostimen käyttömahdollisuudet. Opinnäytetyössään "Kangastulostaminen, Amber -kangastulostin ja sillä toteutettu mallisto" hän tutki suunnittelu- ja toteutusmahdollisuudet eri kangaslaaduille, värin kiinnitystekniikat sekä kankaiden esikäsittelymenetelmät. Hän tutki myös kuvan muuttamista oikeaan formaattiin sähköisessä muodossa. Tulostinta kokeiltiin myös teollisesti kasviväreillä värjätylle pohjamateriaalille. Pohjana käytettiin Laikola Oy:ssä värimorsingolla värjättyä pellavakangasta, johon tulostus tehtiin reaktiiviväreillä. Kangas esikäsiteltiin ennen tulostusta reaktiivivärien apukemikaaleilla, urealla ja kalsinoidulla soodalla. Tulostuksen jälkeen reaktiiviväri kiinnitettiin höyryttämällä.

Opinnäytetyöntekijä Sirpa Kinnunen tutki työssään "Kuvia ja Kerroksia, tietokoneavusteinen kudonta" uuden tietokoneavusteisen jaquard-kudontalaiteen, Thread Controller-1, käyttöä kudottujen tekstiilien kuvioinnissa. Tietokoneavusteinen jaquard-kudontalaite mahdollistaa valokuvamaisenkin työn kutomisen kangaspuilla. Työ suunnitellaan ja sidostetaan tietokoneella, jonka jälkeen kudonta tapahtuu käsityömäisesti. Työn lähtökohtana voi olla valokuva, digitaalinen kuva ym. Tietokone ohjaa jokaisen langan nousua tai laskua viriöön yhden langan tarkkuudella, joten hyvinkin yksityiskohtaisten kuvien tekeminen on mahdollista. Sirpa käytti työssään teollisesti japanin väritatarilla ja värimorsingolla värjättyjä pellavalankoja ja kutoi mm. värimorsingon kuvan mustaan vakioloimeen.

\section{Johtopäätökset}

Suomessa viljellyt indigokasvit soveltuvat mainiosti tekstiliteollisuuden värin lähteiksi. Värjäysprosessit ovat yksinkertaisia ja onnistuvat hyvin sekä käsityömäisessä- että teollisuusmittakaavassa. Suurempia värjäyseriä tehtäessä ongelmaksi muodostuu värin olomuoto, valmis liuos. Nyt tehdyt koevärjäykset olivat vielä hyvin pienimuotoisia. Normaali teollisuusvärjäys esim. Laikolan värjäämössä vaatii liemimääräkseen 2500 I lientä, jonka kuljetus ja varastointi liemimuodossaan on jo hyvin hankalaa. Väri pitäisikin saada hyvin tiiviiseen, konsentroituun muotoon, jota olisi helppo kuljettaa, varastoida ja käsitellä. Myös kasvi-indigon käyttö kankaanpainomenetelmissä vaatisi väriaineen saamista pulverimaisessa, hyvin puhtaassa muodossa.

Kestoiltaan kasvi-indigot ovat kaikista luonnonväriaineista parhaimpia, joten niiden tuotteistaminen valmiiksi tuotteiksi asti olisi täysin mahdollista. Ainoa ongelma, joka tulee vastaan, on materiaalin värisävyn muutos ensimmäisen pesun jälkeen. Tämä kuluttajalle epämiellyttävä yllätys saadaan vältettyä sillä, että tuote tai materiaali pestään kertaalleen ennen markkinoille tuloa. Indigovärjätyille materiaaleille suositellaan kertapesua materiaalista riippuen 60-80 C kaksi viikkoa värjäyksen jälkeen, jolloin tuotteessa ollut irtoväri irtoaa ja samalla materiaali saa lopullisen sävynsä. Tämä yksi ylimääräinen käsittely tosin lisää tuotteen kustannuksia jonkin verran. Teollisuusvärjäyksissä luonnonindigot käyttäytyivät täysin samoin kuin synteettiset indigoväriaineet. Ennenkuin tekstiiliteollisuus saadaan vakuuttumaan Suomessa viljellystä sinisestä väristä, tulisi vielä tehdä jatkotutkimusta esim. värisävyn toistuvuudesta eri satovuosina sekä värin kylmäeristysmenetelmistä ja eri eritysmenetelmien vaikutuksesta lopulliseen värisävyyn. Ranskalainen yritys Sarl Bleus de Pastel de Lectoure tuotteistaa jo varsin laajamittaisesti Ranskassa viljeltyä värimorsinkoa, joten suomalaisillekin kasvi-indigoille löytynee omat markkinointiväylänsä jatkossa. 
Niinimäki, Kirsi: Värimorsinkoa Ranskasta. Kauno 2, EVTEK Muotoiluinstituutti, Kasvivärien tuotekehitysprojekti, Keili,Helsinki, kevät 2003

Niinimäki, Kirsi: Opinnäytetyöt keväällä 2003. Kauno 3, EVTEK Muotoiluinstituutti, Kasvivärien tuotekehitysprojekti, Keili, Helsinki, syksy 2003

Aalto-Kallonen, Tuovi: Sinistä morsingosta-kyyppivärjäyksen työvaiheet. Kauno 3, EVTEK Muotoiluinstituutti, Kasvivärien tuotekehitysprojekti, Keili, Helsinki, syksy 2003

Balfour-Paul, Jenny: Indigo. British Museum Press a division of British Museum Company Ltd, London, England, 1998

Seefelder, Mathias: Indigo in culture, science and technology. AG \& Co.KG, Landsberg, Germany.1994

Edmond B.SC, John: The history of woad and the medival woad vat. Historic dyes series no 1. John Edmonds, Buckinghamshire. England, 1998

Sandberg, Gösta: Indigo textiles, technique and history. Lark Books, Hong Kong, 1989

Forss, Maija: tekstiilivärjäyksen uusia tuulia. Painatuskeskus Oy, Helsinki, 1993

Forss, Maija: Värimenetelmiä. Värjäys, maalaus, kankaanpainanta. Gummerus Kirjapaino Oy, Jyväskylä, 2000 